\title{
Effects of supplemental lighting using HPS and LED lamps with different light spectra on growth and yield of the cucumber (Cucumis sativus L.) during winter cultivation in greenhouse
}

\author{
Jadwiga Treder*, Anna Borkowska, Waldemar Treder, Kalina Sikorska-Zimny
}

Research Institute of Horticulture, 96-100 Skierniewice, Poland

\begin{abstract}
The aim of the experiment was to assess the effects of supplemental lighting of cucumber grown in greenhouse using lamps with differentiated light spectra: sodium lamps - high-pressure sodium (HPS) and light emitting diodes (LEDs). Plants (cucumber 'Pacto' $F_{1}$ ) were grown in two greenhouse compartments with five light treatments: I - HPS + LED (top light with HPS LEDs as interlighting), II - only HPS as top light, III - LED R (LED chips on board (COB) type with an increased level of red band), IV - LED W (LED COB type, white), V - LED B (LED COB type with an increased level of blue spectrum). Light treatments: HPS + LEDs and HPS were grown in one greenhouse compartment and the other three light treatments: LED R (red light supplementation), LED W (without additional supplementation) and LED B (red spectrum supplementation) in the second compartment in analogous climatic conditions. The LED lamps using COB technology are known to be a very efficient source of light. Plants were cultivated from December 2018 to March 2019 in mineral wool slabs Grotop Master $(100 \times 15 \times 10)$ with four plants on one mat. They were illuminated for $18 \mathrm{~h}$ (from 5 am to $11 \mathrm{pm}$ ), setting the threshold value (on and off) at $130 \mathrm{~W}$. The plants were drip-irrigated with a complete nutrient solution. The irrigation was controlled based on a weighting system. The assessment of the effect of lighting on early yield and quality of cucumbers was completed after 8 weeks of cropping. It was shown that it was possible to obtain $3.59 \mathrm{~kg}$ from one plant during the 8 -week period of evaluation by illuminating plants with sodium lamps (HPS), while using HPS and LEDs as additional illuminated inter-rows $3.89 \mathrm{~kg}$. The yield of plants illuminated by LED lamps varied depending on the variant of the spectrum used and was respective for LED R, LED W and LED B, $3.30 \mathrm{~kg}, 3.90 \mathrm{~kg}$ and $3.25 \mathrm{~kg}$. The obtained results indicated that the yield of cucumber 'Pacto' $F_{1}$ grown with HPS lamps at top lighting and at the same time using interlighting with LED lamps was similar to LED W lamps (i.e. without additional supplementation in the range of red (LED R) and blue (LED B) light). Due to good results of LED lamps (type COB for top lighting or as interlighting) used for the cucumber supplemental lighting and high energy efficiency of LEDs, the promising future for that type of lamps compared with traditionally used HPS during winter cultivation in a greenhouse was demonstrated.
\end{abstract}

Keywords: Cucurbitaceae, greenhouse cultivation, growth parameters, high-pressure sodium lamps, LEDs COB, light spectra

\section{INTRODUCTION}

Cucumbers are grown intensively in greenhouses in soilless systems all over the year because of the high demand of the market. During winter months, owing to lack of natural light, yield and fruit quality are usually insufficient and cultivation is not economically profitable. Cucumbers, due to their high demand for heat and good cultivation technology (soilless cultures, well-equipped greenhouses) cannot be grown without supplemental lighting the whole year. Traditionally used sodium lamps (high-pressure sodium [HPS]) in greenhouse crops are usually the main source of light in winter months, although light emitting diodes (LEDs) are becoming more and more common in horticulture (Massa et al., 2008; Morrow, 2008; Mitchell et al., 2012). 
The LED lamps using chips on board (COB) technology are known to be a very efficient source of light

Because of greater efficiency of LED lamps and a possibility of light spectra regulation, this kind of supplemental lighting is more often used not only in research but also in production (Mitchell et. al., 2012, Pattinson et al., 2016; Virš̀ile et al., 2017; Samoulienè et. al., 2019). However, it appears that the most important factor conducive to spreading the technology of LED application in horticulture is high electrical efficiency, especially in LED lamps constructed in COB. Light intensity and quality are exceptionally important factors for many horticultural plants grown in the northern hemisphere during winter months (Blom and Ingratta, 1984). Even though other growth factors such as cultivation time, good initial plant quality, microclimate in a greenhouse and fertigation are within the optimal range, yield and fruit quality are influenced significantly by light availability (Kowalczyk et al., 2018). Positive effects of LED lighting for vegetables growth and yield were shown by many researchers (Massa et al., 2008; Gajc-Wolska et al. 2013; Olle and Virsille 2013; Kowalczyk et al., 2018; Kowalczyk et al., 2020). Light penetration from the top of plant canopy to the lower leaves is often obstructed in case of highgrowing plants like tomatoes, cucumbers and bell-peppers in greenhouse cultivation. Therefore, the application of LEDs with a special construction that enables to use them as interlights mounted between the plant rows is recently being developed. Pettersen et al. (2008) showed that this type of supplemental lighting increased yield and quality of fruits via increased photosynthesis of medium and bottom leaves of cucumbers.

The aim of the experiment was to evaluate the influence of two light sources (HPS and LEDs) and different light spectra characteristics on growth and yield of cucumber 'Pacto' $\mathrm{F}_{1}$ during winter cultivation.

\section{MATERIALS AND METHODS}

The experiment was performed in two separate climatecontrolled greenhouse compartments of the Research Institute of Pomology and Floriculture in Skierniewice, Poland, from December 2018 until March 2019. Fourweek-old seedlings of cucumber (Cucumis sativus L.) 'Pacto' $F_{1}$ raised in mineral wool cubes $10 \times 10 \mathrm{~cm}$ were planted on wool mats (Grotop Master, $100 \times 15 \times 10$ ) with four plants on each one. Five different supplemental light treatments were applied: I - HPS + LED (top light with HPS and LEDs as interlighting), II - only HPS as top light, III - LED R (LED COB type with an increased level of red band), IV - LED W (LED COB type, white), V LED B (LED COB type with an increased level of blue spectrum). Lamps (LED and HPS) spectra characteristics are presented in Table 1. LED COB lamps with possibility or spectra light and intensity regulation were prepared by Spectrolight (Łodz), LEDs for interlighting were prepared by Instytut Elektrotechniki (Warsaw). Light intensity and spectra characteristics were measured using Lighting Passport Spectrometer. Light treatments:
HPS + LEDs and HPS were grown in one greenhouse compartment and the other three: LED R, LED $\mathrm{W}$ and LED B in the second compartment in analogous climatic conditions. Plants were illuminated for $18 \mathrm{~h}$ (from 5 am to $11 \mathrm{pm}$ ), setting the threshold value (on and off) at $130 \mathrm{~W}$. The photosynthetically active radiation at the plant level at planting was $120 \pm 20 \mu \mathrm{mol} \cdot \mathrm{m}^{-2} \cdot \mathrm{s}^{-1}$. The plants were drip-irrigated with a complete nutrient solution. They were fertilised according to the plant requirements using a complete nutrient solution (EC - electroconductivity 2.1-2.3, pH 5.5-5.9), contained $\left(\mathrm{mg} \cdot \mathrm{dm}^{-1}\right)$ NPK (nitrogen, pottasium and phosphorus) at 200, 31.5 and 260, respectively, and microelements. The irrigation frequency was controlled using the weighting system and humidity sensors fixed onto the growing mats. The temperature in the greenhouse compartments was kept at $22-24^{\circ} \mathrm{C} / 18$ day/ night, relative air humidity at $60-70 \%$. Plants were grown without $\mathrm{CO}_{2}$ supplementation. The climate control in the greenhouse was controlled using Priva system. The first fruit buds (five to six on each plant) were removed. Regular fruit harvest started after 4 weeks of cultivation. The assessment of the effect of lighting on early yield and quality of cucumbers was completed after 8 weeks of cropping. According to the length of harvested fruits, they were divided into two groups: shorter and longer than $20 \mathrm{~cm}$. The fruit was harvested, measured and weighed every 2-3 days, when fruits reached 180-230 g. The results are presented on figures as total yield of fruits during 8 weeks of evaluation, yield of fruits longer than $20 \mathrm{~cm}$ and the percentage of long fruits $(>20 \mathrm{~cm})$ in total yield of cucumbers. Fruit quality was expressed as total soluble salt (TSS) and vitamin C content was evaluated twice (March 7 and 14, 2019). TSS was measured with refractometer HI 9601 (Hanna Instr.) and vitamin C with Tilmann's reagent. Differences between the obtained results were presented graphically and statistical differences between the treatments were assessed using a standard error (SE). There were 16 plants in each treatment and each plant was considered as repetition. The calculation was performed using Statistica 14.0 (StatSoft Inc., USA).

\section{RESULTS AND DISCUSSION}

The first harvest crop of cucumbers was obtained on 25 January 2019 (fourth week of the year). After 8 weeks of cropping, the obtained results showed that cucumber plants illuminated exclusively with sodium lamps (HPS) gave 3,590 g from one plant during that period, while using HPS as top lighting and additional light as interrows 3,890 g (Figure 1). The yield of plants illuminated exclusively by LEDs lamps varied depending on the variant of the spectrum applied and was respective for LED R (red light supplementation), LED W (without additional supplementation) and LED B (blue spectrum supplementation), 3,300 g, 3,900 g and 3,250 g. The differences between fruit yield from I treatment (HPS and LED as interlights) and IV treatment (LED W) were 
Table 1. Characteristic of light spectra of lamps used for experiment with cucumber 'Pacto' $F_{1}$ cultivation.

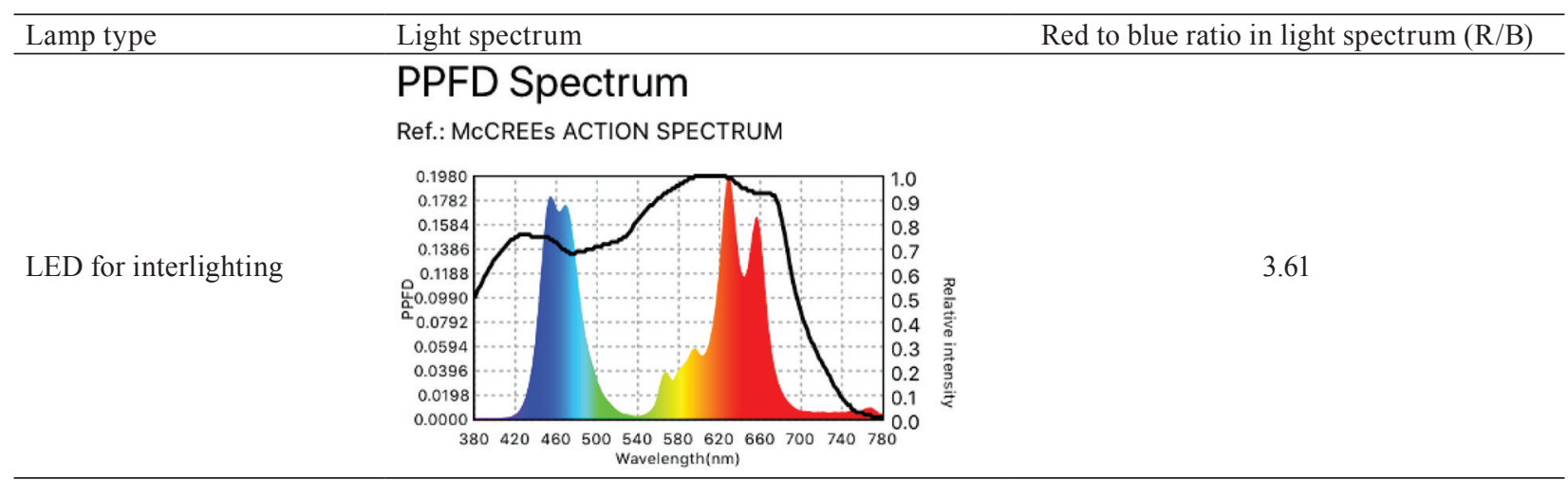

\section{PPFD Spectrum}

\section{Ref.: MCCREES ACTION SPECTRUM}

HPS

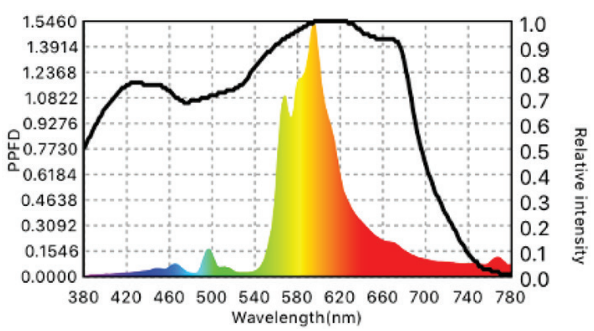

\section{PPFD Spectrum}

Ref.: MCCREES ACTION SPECTRUM

$\mathrm{LED} \mathrm{COB}+$ red

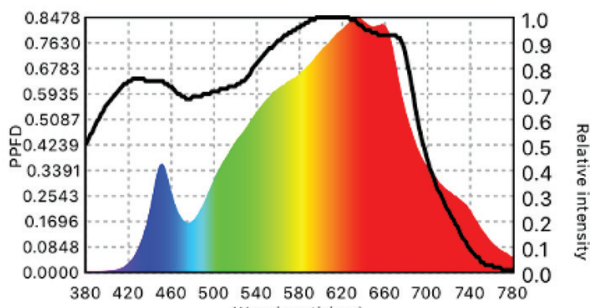

\section{PPFD Spectrum}

Ref.: MCCREES ACTION SPECTRUM

LED COB white

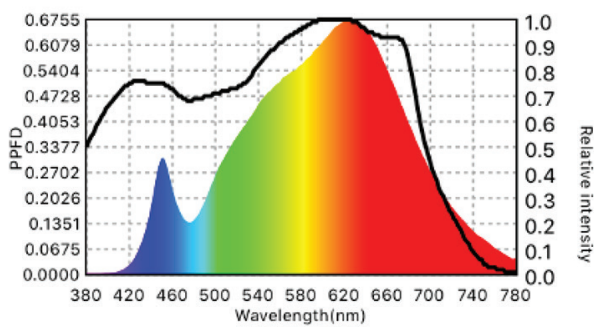

\section{PPFD Spectrum}

Ref.: MCCREES ACTION SPECTRUM

LED COB + blue

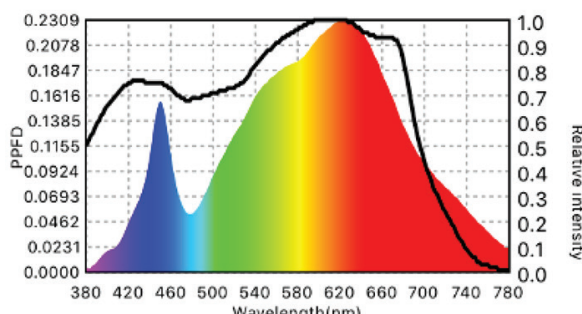




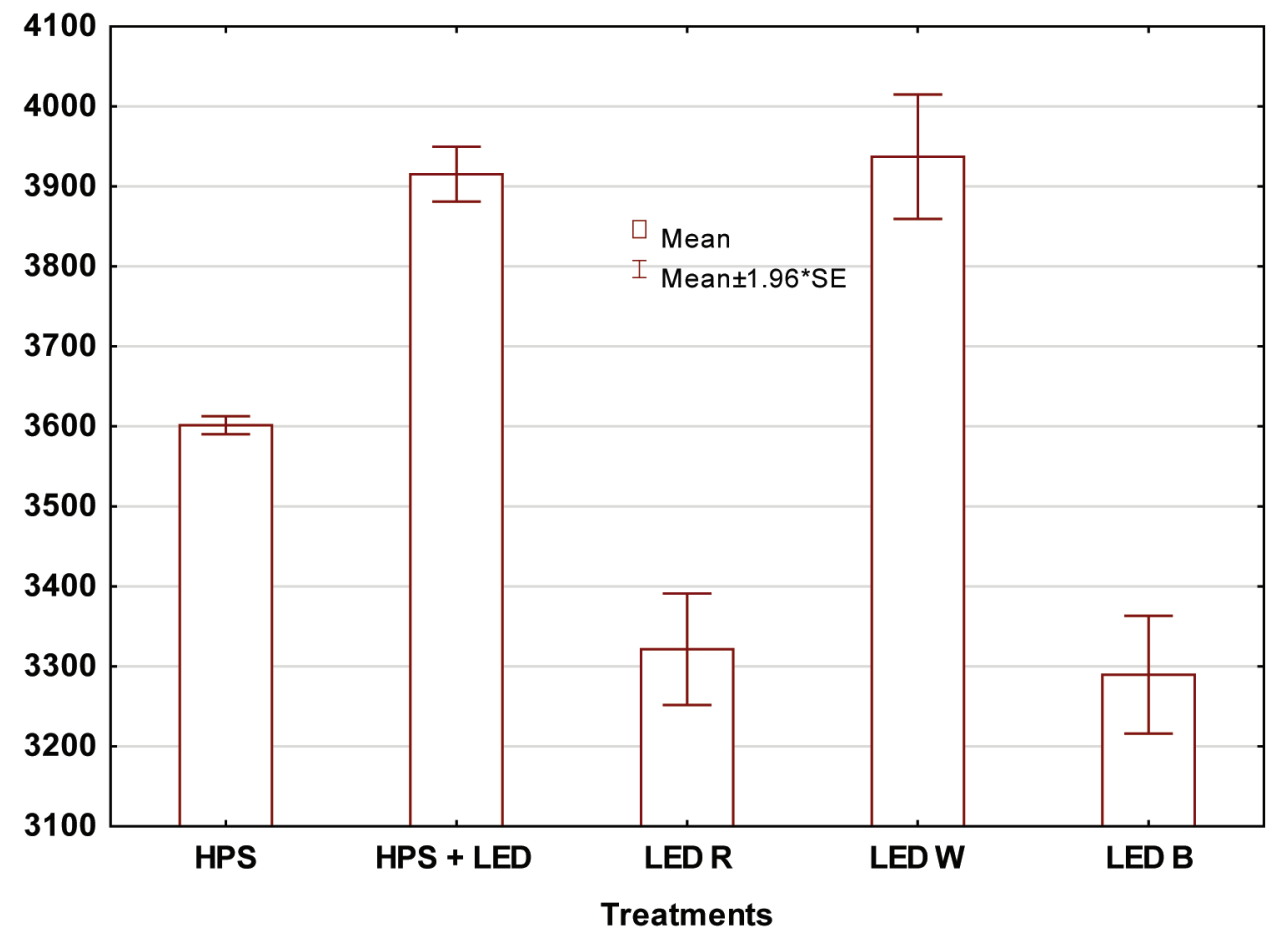

Figure 1. Total fruit yield of cucumber 'Pacto' $F_{1}\left(g \cdot\right.$ plant $\left.^{-1}\right)$ during 8 weeks of cropping. HPS, high-pressure sodium; LED, light emitting diode; SE, standard error.

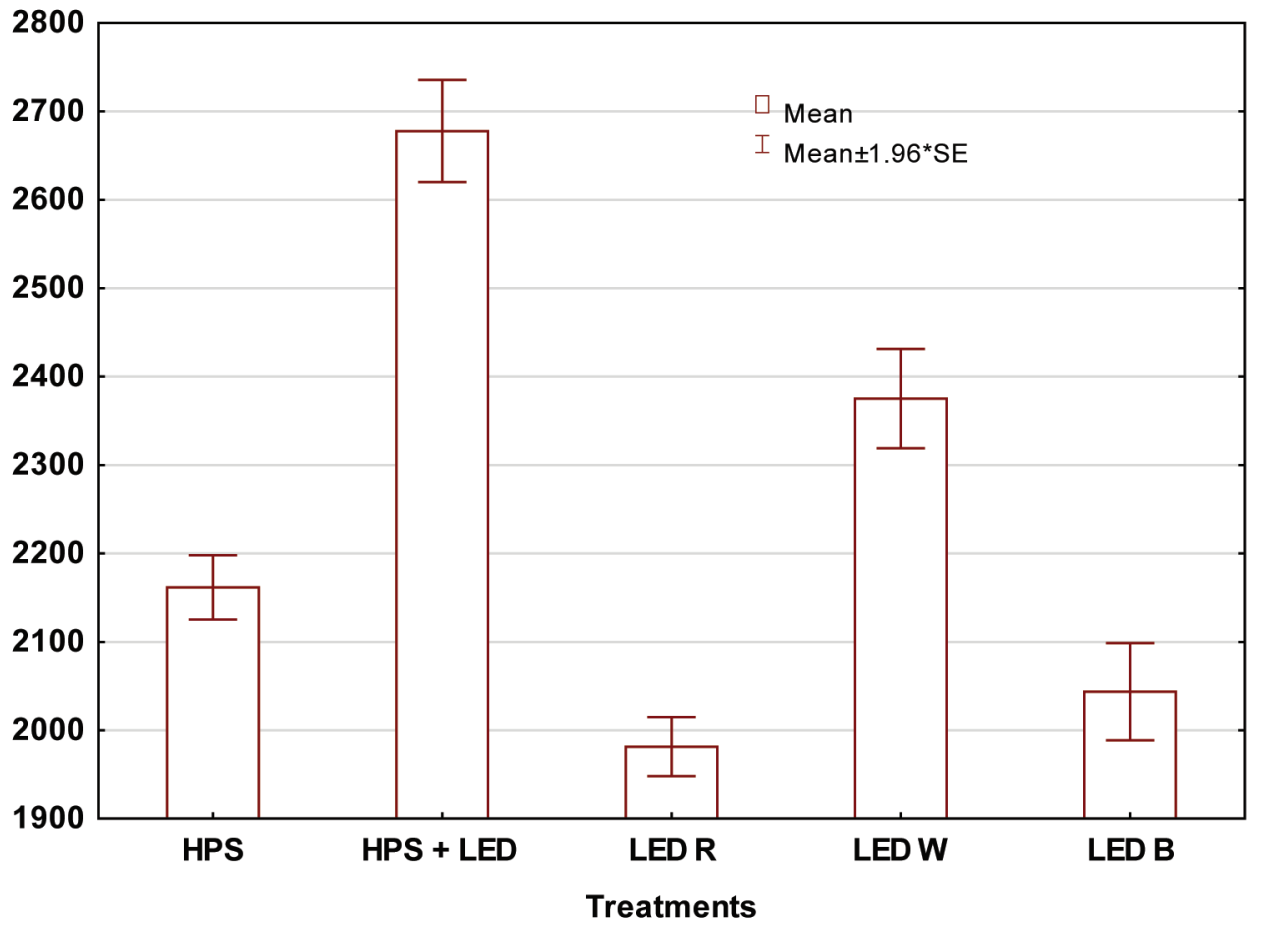

Figure 2. Fruit yield (length $>20 \mathrm{~cm})\left(\mathrm{g} \cdot\right.$ plant $\left.^{-1}\right)$ of cucumber 'Pacto' $\mathrm{F}_{1}$ during 8 weeks of cropping. HPS, highpressure sodium; LED, light emitting diode; SE, standard error.

not significant. Treatments of cucumbers with LED B (blue spectrum supplementation), with the lowest ratio B:R (2.66), gave lower fruit yield compared with other light treatments.

The obtained results indicated that the yield of 'Pacto' $\mathrm{F}_{1}$ cucumber illuminated by HPS lamps and at the same time inter-row LED lamps were similar to LED W lamps (i.e. without additional supplementation in the range of red and blue spectrum). Comparing the fruit quality (fruit length), the highest yield of fruit longer than $20 \mathrm{~cm}$ at harvest, the best results were observed in case of treatment I - with HPS and LEDs (Figure 2). The lowest yield of fruit longer than $20 \mathrm{~cm}$ gave plants grown with LED B and LED R. However, comparing the percentage 


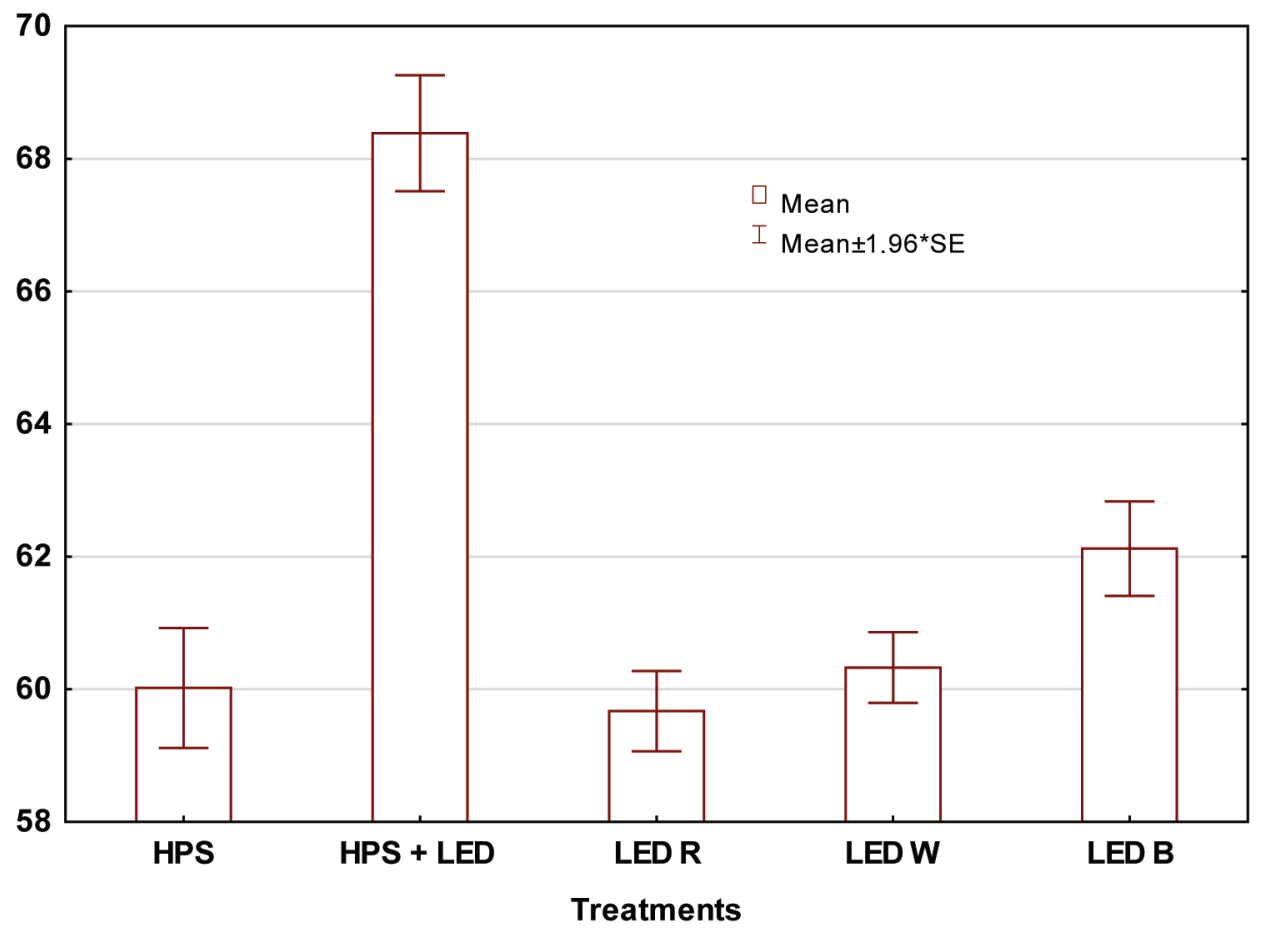

Figure 3. Percentage of fruits longer than $20 \mathrm{~cm}$ in the total yield of cucumber 'Pacto' $F_{1}$ during 8 weeks of cropping. HPS, high-pressure sodium; LED, light emitting diode; SE, standard error.

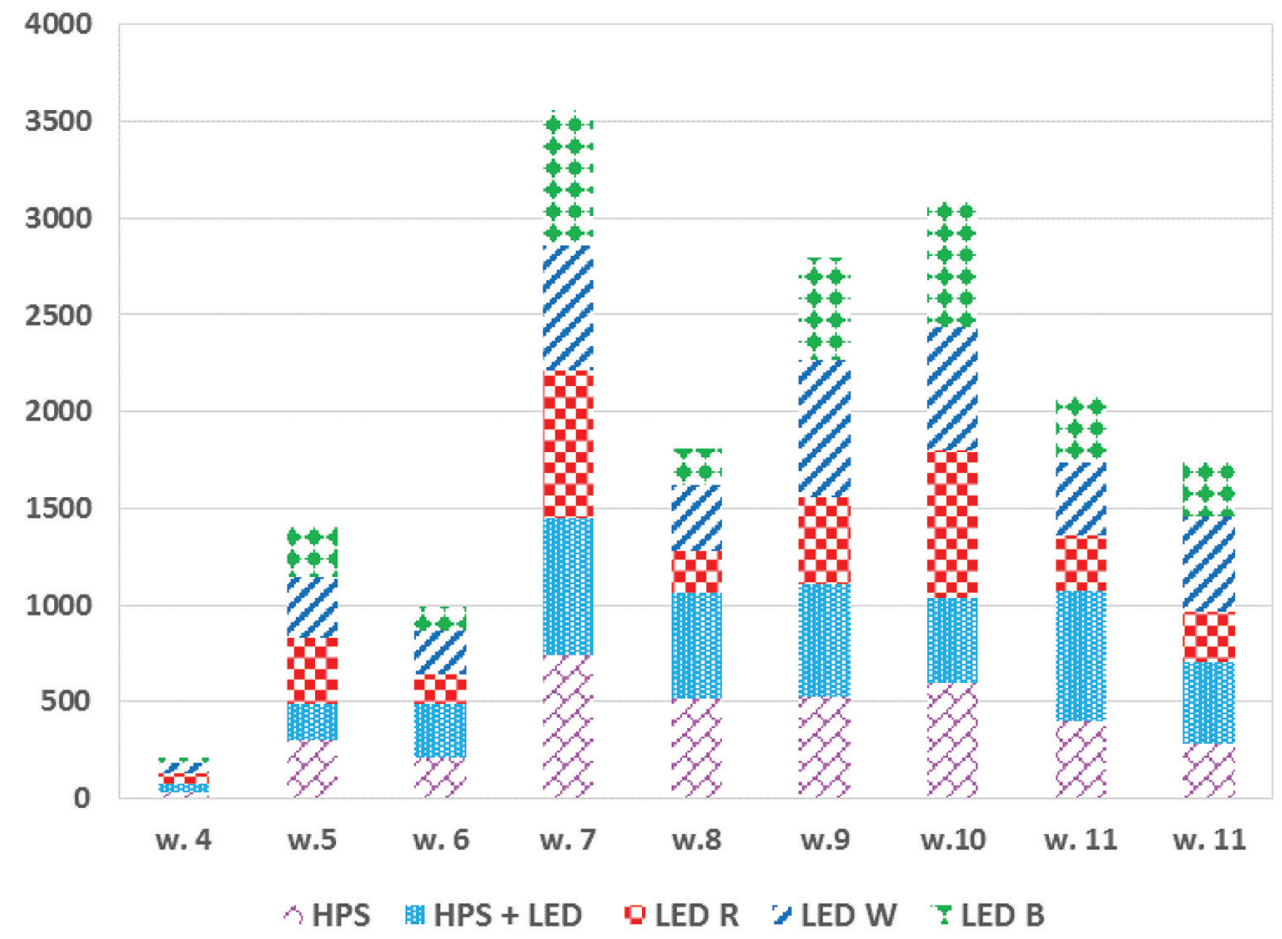

Figure 4. Weekly yield (weeks counted from the first week of January) of cucumber 'Pacto' $\mathrm{F}_{1}\left(\mathrm{~g} \cdot \mathrm{plant}^{-1}\right)$ in relation to light treatments. HPS, high-pressure sodium; LED, light emitting diode.

of fruits longer than $20 \mathrm{~cm}$ in the total yield, the best results were observed in case of I treatment - HPS and LED interlighting and subsequently of treatment V - LED B - supplemented with B wavelength (Figure 3). The positive effects of using LEDs as interlights for cucumbers were also observed by Kowalczyk et al. (2018),
Hao et al. (2012), Hovi-Pekkanen and Tahvonen (2008), Hovi et al. (2004). High yield and good fruit quality of cucumber 'Svyatogor' $F_{1}$ grown with LED as top light with additional two lines of LED inter-row light lighting were also shown by Kowalczyk et al. (2020). It seems the cucumber being a thermophilic plant has the best 
Table 2. The content of vitamin C and TSS evaluated at two dates of measurements: I - 7 March and II - 14 March.

\begin{tabular}{|c|c|c|c|c|c|}
\hline \multirow[t]{2}{*}{ Date of measurement } & \multirow[t]{2}{*}{ Light treatment } & \multicolumn{2}{|c|}{ Vitamin $\mathrm{C}$} & \multicolumn{2}{|c|}{ TSS } \\
\hline & & $\mathrm{mg} \cdot 100 \mathrm{~g}^{-1} \mathrm{FM}$ & $\mathrm{SD}$ & ${ }^{\circ}$ Brix & $\mathrm{SD}$ \\
\hline \multirow{5}{*}{7 March } & I - HPS + LED & 2.20 & 0.29 & 3.37 & 0.12 \\
\hline & II - HPS & 1.44 & 0.18 & 3.13 & 0.05 \\
\hline & III - LED R & 1.63 & 0.22 & 3.33 & 0.17 \\
\hline & IV - LED W & 1.68 & 0.18 & 3.20 & 0.14 \\
\hline & $\mathrm{V}-\mathrm{LED} \mathrm{B}$ & 1.59 & 0.14 & 3.37 & 0.05 \\
\hline \multirow{5}{*}{14 March } & I - HPS + LED & 2.85 & 0.01 & 3.13 & 0.05 \\
\hline & II - HPS & 2.00 & 0.15 & 3.03 & 0.05 \\
\hline & III - LED R & 1.78 & 0.24 & 3.10 & 0.00 \\
\hline & IV - LED W & 1.90 & 0.26 & 3.03 & 0.05 \\
\hline & $\mathrm{V}-\mathrm{LED} \mathrm{B}$ & 2.27 & 0.03 & 2.97 & 0.05 \\
\hline
\end{tabular}

HPS, high-pressure sodium; LED, light emitting diode; SD, standard deviation; TSS, total soluble salts.

conditions for growing and fruit development with HPS (emitting heat) used as a top light and additionally with LED interlights, which may improve photosynthetical activity of medium and bottom leaves significantly. This phenomenon in cucumbers was observed by Sarkka et al. (2017), Pettersen et al. (2008), Trouwborst et al. (2010). The weekly yields of fruits on each light treatment are presented in Figure 4.

The application of LED as interlights together with HPS as top light (treatment I) gave the highest vitamin C content in cucumber fruit and the highest TSS readings, comparing with other light treatments in both dates of fruit evaluation (Table 2). Higher level of vitamin $\mathrm{C}$ in all treatments observed at the second date of measurements can be influenced by better access to light of fruits being closer to the top of plants and of course higher natural light intensity in the mid-March period. Grzelakowska et al. (2013) and Wierzbicka and Kuskowska (2002) showed that vitamin $\mathrm{C}$ content in cucumber fruits can vary according to climate condition during cultivation, especially when plants are grown at low temperature. Migut et al. (2018) obtained exactly the same content of vitamin $\mathrm{C}\left(2.8 \mathrm{mg} \cdot 100 \mathrm{~g}^{-1}\right)$ in cucumber fruits as in the present study shown in treatment I (HPS as top light and LED as interlights) in the second date of evaluation. In case of TSS of cucumber fruits, the values varied according to the different light treatments from 2.97 Brix to $3.13^{\circ}$ Brix. These results are similar to these obtained on cucumbers by Reddy et al. (2018), which varied between 2.8 and $2.9^{\circ}$ Brix and slightly lower than was shown by Mulla et al. (2018), who obtained $3.9^{\circ}$ Brix. The results of the present study confirm the other research on cucumber during winter cultivation than HPS as top light and LED as interlighting can increase the yield, gave higher percentage of long fruits and significantly can improve fruit quality expressed as vitamin $\mathrm{C}$ content and TSS in fruit flesh. Interlighting LED lamps are also beneficial for other greenhouse crops like the tomato (Menard et al., 2006; Gómez and Mitthel, 2014), and bell-peppers (Joshia et al., 2019).

\section{CONCLUSIONS}

1. The advisability of lighting cucumbers with LED lamps during cultivation in autumn and winter, especially as interlighting lamps, was demonstrated due to good quality of fruits and to the high energy efficiency of LED lamps.

2. Cucumbers grown with HPS lamps as a top and LED as interlighting gave the highest early yield with fruits with the highest content of vitamin $\mathrm{C}$ compared with other light treatments

3. Due to high-temperature requirements of cucumber, it seems that mixed system for this plant (HPS and LED with full light spectrum or LED as interlighting) is the best solution to obtain high and early yield of fruits.

\section{FUNDING}

The research was conducted as a part of the task of Multiannual Program of Polish Ministry of Agriculture, 2015-2020, Task 3.1 "Development of Water-Saving and Energy-Saving Horticultural Technologies”.

\section{AUTHOR CONTRIBUTIONS}

J.T. planned and conducted the experimental work and manuscript writing. A.B. collected and obtained data elaborately. W.T climate control in greenhouse. K.S-Z analyses of biological fruit quality.

\section{CONFLICT OF INTEREST}

Authors declare no conflict of interest.

\section{REFERENCES}

Al-Mulla, Y. A., Al-Balushi, M. I., Al-Busaidi, H. A., Al-Mahdouri, A. A., Kittas, C., And Katsoulas, N. (2018). Analysis of microclimate and cucumber fruit yield in a screenhouse and an evaporatively cooled greenhouse in a semi-arid location. Transactions of the ASABE, 61(2), 619-629. 
Blom, T. J., And Ingratta, F. J. (1984). The effect of high-pressure sodium lighting on the production of tomatoes, cucumbers and roses. Acta Horticulturae, 148, 905-914.

Brazaitytè, A., Duchovskis, P., Urbonavičiūtè, A., SAmuoliené, G., Jankauskienè, J., KasiulevičiūtéBonaKéré, A., BlizniKas, Z., NovičKovas, A., Breivė, K., AND ŽUKAUSKAS, A. (2009). The effect of light-emitting diodes lighting on cucumber transplants and aftereffect on yield. Zemdirbyste-Agriculture, 96, 102-118.

Gajc-Wolska, J., KowalczyK, K., Metera, A., Mazur, K., Bujalski, D., and Hemka, L. (2013). Effect of supplementary lighting on selected physiological parameters and yielding of tomato plants. Folia Horticulturae, 25(2), 153-159.

Gómez, C., And Mitchell, C. A. (2014). Supplemental lighting for greenhouse-grown tomatoes: Intracanopy LED towers $v s$. overhead HPS lamps. Acta Horticulturae, 1037, 855-862.

Grzelakowska, A., Cieślewicz, J., and Ludzińska, M. (2013). The dynamics of vitamin $\mathrm{C}$ content in fresh and processed cucumber (Cucumis sativus L.) Versita. Chemistry-Didactics-Ecology-Metrology, 8(1-2): 97-102.

Hao, X., Zheng, J. M., Little, C., Khosla, S. Hernández, R., Dragotakes, A., and Kubota, C. (2012). Pulsing effects of supplemental LED lighting on cucumber seedlings growth and morphology in greenhouse. Acta Horticulture, 1037, 875-880.

Hovi-Pekkanent, T., and Tahvonen, R. (2008). Effects of interlighting on yield and external fruit quality in year-round cultivated cucumber. Scientia Horticulturae, 116, 152-161.

Hovi, T., Nakkila, J., And Tahvonen, R. (2004). Interlighting improves production of year-round cucumber. Scientia Horticulturae, 102, 283-294.

Joshia, N. C., Ratner, K., Eidelman, O., Bednarczyk, D., Zur, N., Many, Y., Shahak, Y., Aviv-Sharon, E., Achiam, M., GILAD, Z., AND CHARUVI, D. (2019). Effects of daytime intra-canopy LED illumination on photosynthesis and productivity of bell pepper grown in protected cultivation. Scientia Horticulturae, 250, 81-88.

Kowalczyk, K., Gajc-Wolska, J., Bujalski, D., Mirgos, M., Niedzińska, M., Mazur, K., ŻoŁnierczyk, P., SZATKOWSKi, D., CiChOŃ, M., AND ŁęCZYCKA, N. (2018). The effects of supplemental assimilation lighting with HPS and LED lamps on the cucumber yielding and fruit quality in autumn crop. Acta Scientiarium Polonorum Hortorum Cultus, 17(4), 193-200.

Kowalczyk, K., Gajc-Wolska, J., Mirgos, M., Geszprych, A., Kowalczyk, W., SieczKo, L., NiedzińsKa, M., AND Gajewski, M. (2020). Mineral nutrients needs of cucumber and its yield in protected winter cultivation, with HPS and LED supplementary lighting. Scientia Horticulturae, 265, 109-217.

KowalczyK, K., Olewnicki, D., Mirgos, M., And GajC-WolsKa, J. (2020). Comparison of selected costs in greenhouse cucumber production with LED and HPS supplemental assimilation lighting. Agronomy, 10, 1342, doi: 10.3390/agronomy10091342.
Massa, G. D., Kim, H-H., Wheeler, R. M., ANd Mitchell, C. A. (2008). Plant productivity in response to LED lighting. HortScience, 43, 1951-1956.

Menard, C., Dorais, M., Hovi, T., and Gosselin, A. (2006). Developmental and physiological responses of tomato and cucumber to additional blue light. Acta Horticulturae, 711, 291-296.

Migut, D., Skrobacz, K., and Gorzelany, J. (2018). Evaluation of vitamin $\mathrm{C}$ content in fresh and pickled cucumber fruits. Applied Biosciences, 1(3), 27-28.

Mitchell, C. A., Both, A. J., Bourget, M. C, Burr, J. F., Kubota, C., Lopez, R. G., Morrow, R. C., And RunkLE, E. S. (2012). LEDs: The future of greenhouse lighting. Chronica Horticulture, 52, 6-12.

Morrow, R. C. (2008). LED lighting in horticulture. HortScience, 43(7), 1947-1950.

Olle, M., AND Viršile, A. (2013). The effect of light emmiting diode lighting on greenhouse plant growth and quality. Agricultural and Food Sciences, 22(2), 223-234.

Pattison, P. M., Tsao, J. Y. and Krames, M. R. (2016). Light-emitting diode technology status and directions: opportunities for horticultural lighting. Acta Horticulturae, 1134, 413-426.

Pettersen, R. I., Moe, R., And Gislerod, H. R. (2008). Effects of intracanopy lighting on photosynthetic characteristics of cucumber. In R. I. Pettersen (Ed.), The role of supplemental light duration in production of cucumber and roses. Ås, Norway: Norwegian University of Life Sciences.

Reddy, M. S., Chauhan, A. S., and Maloo, S. (2018). Impact of enzymatic treatment on physicochemical properties of various vegetable juices. The Pharma Innovation Journal, 7(11), 318-323.

Samuoliené, G., Brazaitytė, A., and Vaštakaité, V. (2017). Light emitting diodes (LEDs) for improved nutritional quality. S. Dutta Gupta (Ed.), Light emitting diodes for agriculture (pp. 149-190). Singapore: Springer.

SarkKa, L. E., Jokinen, K., Ottosen, C. O., And Kaukoranta, T. (2017). Effects of HPS and LED lighting on cucumber leaf photosynthesis, light penetration and temperature in the canopy, plant morphology and yield. Agricultural and Food Sciences, 26(2), 102-110.

Troumborst, G., Oosterkamp, J., Hogewoning, S. W., Harbinson, J., and Van Ieperen, W. (2010). The responses of light interception, photosynthesis and fruit yield of cucumber to LED-lighting within the canopy. Physiologia Plantarum, 138, 289-300.

Virśile, A., Olle, M., AND Duchovskis, P. (2017). LED lighting in horticulture. S. Dutta Gupta (Ed.), Light emitting diodes for agriculture (pp. 113-147). Singapore: Springer.

WierzBicka, B., And Kuskowska, M. (2002). Wpływ wybranych czynników na zawartość witaminy C w warzywach. Acta Scientiarium Polonorum, Hortorum Cultus, 1(2), 49-57.

Received: October 11, 2020; accepted: December 31, 2020. 